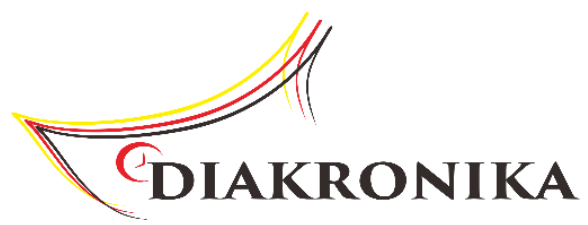

Vol. 19 No. 2 Th. 2019 p: 93-108

ISSN: 1411-1764 (Print) | 2620-9446 (Online)

http://diakronika.ppj.unp.ac.id

\title{
Muatan Lokal Nahdlatul Wathan untuk Menggali Nilai-Nilai Nasionalisme di Madrasah Aliyah Kota Mataram
}

\author{
Faidin, Agus Mulyana, Helius Sjamsuddin \\ faidinhistory94@gmail.com \\ Universitas Pendidikan Indonesia
}

\begin{abstract}
Nahdlatul Wathan local content is particulary learning in Nahdlatul Wathan organization. It is expected that the implementation of this learning can explore the values of nationalism in establishing the national identity and national spirit. The purpose of this research is to describe the implementation of Nahdlatul Wathan local content in exploring the values of nationalism. This also describes the internalization and crystallization of the nationalism values in teaching Nahdlatul Wathan, in which it is spearhead of a nation's strenght to respond the global challenges. The research uses a qualitative approach with case study method. The research is depicted the data from students's age up of 17 and the teacher's age is between 22 to 60 years old. The data were obtained through observation, interview, and documentation, those are analyzed by using two approaches, before in the field and during in the field. Futher, analyzing the data were reduction data, display data, and conclusions/verification. The results of the study revealed that the students were very enthusiastic, and felt the implementation of local content, in which the implementation material "Nahdlatul Wathan" with material "the role of Nahdlatul Wathan in nation's building" and "the role of founder's nation of Nahdlatul Wathan" produces the student's the nationalism values of appreciate the heroes and lead higher the eastern values.
\end{abstract}

Keywords: Local Content, Nahdlatul Wathan, Values, Nationalism

\section{Abstrak}

$\overline{T u j u a n}$ artikel ini adalah untuk menguraikan pelaksanaan pembelajaran muatan lokal ke Nahdlatul Wathan-an dalam menggali nilai-nilai nasionalisme. Penelitian ini juga menguraikan internalisasi dan kristalisasi nilai-nilai nasionalisme dalam ajaran Nahdlatul Wathan sebagai ujung tombak kekuatan suatu bangsa dalam menjawab tantangan global. Penelitian ini menggunakan pendekatan kualitatif dengan metode studi kasus. Sumber informan adalah peserta didik yang berumur 17 tahun keatas dan guru berumur antara 22 hingga 60 tahun. Data diperoleh melalui observasi, wawancara, dan dokumentasi yang kemudian dianalisis menggunakan dua pendekatan yakni sebelum di 
lapangan dan selama dilapangan dengan data reduksi, data display, dan Gambaran kesimpulan/Verifikasi. Hasil penelitian menunjukkan bahwa peserta didik sangat semangat dan antusias dalam implementasi muatan lokal nahdlatul wathan, yang mana implementasi materi "peran Nahdlatul Wathan dalam pembangunan bangsa" dan "peran pendiri Nahdlatul Wathan" menghasilkan Peserta didik yang memiliki nilai nasionalisme dalam menghargai pahlawan dan menjujung tinggi nilai ketimuran.

Kata kunci: Muatan Lokal, Nahdlatul Wathan-an, Nilai-Nilai, Nasionalisme.

(c) (i) (2) This work is licensed under the Creative Commons Attribution-ShareAlike 4.0 International License.

\section{Pendahuluan}

Munculnya istilah nasionalisme bukan menjadi suatu hal yang baru. Nasionalisme memberikan sejarah yang luar biasa dalam berbagai periode kehidupan. Era lalu, sekarang bahkan yang akan datang tidak akan pernah berubah, melainkan untuk perkembangan persoalan nasionalisme akan semakin pesat. Awal munculnya nasionalisme untuk pertama kalinya di Eropa pada akhir abad ke-18, pertama bermula pada saat hancurnya kerajaan yang dimulai pada zaman akhir abad pertengahan dan mulai berdirinya negara-negara nasional dengan ciri pokok identifikasi bangsa dalam perorangan yang berkuasa. Kedua, nasionalisme mulai berkembang pada abad ke-19 hingga abad ke-20 diseluruh Eropa bahkan Indonesia, ciri pokok nasionalisme bukan lagi tercermin pada perilaku seorang raja melainkan identitasnya tercermin pada perilaku dari golongan masyarakat tertentu yang memiliki peran besar. Ketiga, nasionalisme berkembang sebagai sosialisasi dari pada bangsa karena adanya loyalitas dari massa (Nusarastriya, 2018).

Pada kenyataannya, perkembangan nasionalisme bersamaan dengan adanya pemahaman dari beberapa ilmuan, yang mana Nasionalisme merupakan paham atau ajaran untuk mencintai bangsa secara potensial dan aktual bersama-sama mencapai, mempertahankan, dan mengabdikan identitas, integritas, dan kekuatan bangsa. Nasionalisme ditekan untuk mempersatukan budaya masa lampau termasuk peninggalan/warisan dan bahasa (Altikulaç \& Sabanci, 2017). Usaha ini merupakan wujud dari semangat kebangsaan yang menjadi tiang utama meraih cinta, rasa suka, dan rasa sepenanggungan. Tercermin ketika kita menjunjung tinggi untuk selalu menghargai sesama. Agustyaningrum, Herman, Waluyo, \& Sumarwati (2018) Indonesian nationalism cannot be separated from 
Faidin, Agus Mulyana, Helius Sjamsuddin

Muatan Lokal Nahdlatul Wathan untuk Menggali Nilai-Nilai Nasionalisme

di Madrasah Aliyah Kota Mataram

the fact that Indonesia has a plural and multicultural society with its diversity and cultural complexity. Aware of diversified gives an unity to do well together.

Nasionalisme dalam pandangan Opafola (2016), bisa mengarah pada keinginan sekelompok masyarakat secara luas (dengan kesamaan ras, asal kelahiran, dan bahasa) untuk membentuk bangsa atau negara yang bebas dari kononialisme dan imperialisme). Keinginan ini, tentu akan dapat terwujud dengan memiliki kesamaan nasib antara masyarakat untuk selalu berjuang dalam membebaskan bangsa. Menurut Yuniyati, W.A., S, Agung. L (2018) a sovereign nation is needed to create a sense of nationalism or love of the country. Sense of national unity becomes one of the great motivations in achieving life prospertity within a country.

Mengutip dari pemikiran Bapak nasionalisme Mesir Al-Afghani, ide nasionalisme bisa hadir secara bersamaan dan justru saling memperkuat satu sama lain, karena nasionalisme dapat mendorong semangat perjuangan, seperti halnya teknologi yang menjadi kekuatan Barat. Hal ini dapat dimanfaatkan sebagai alat perjuangan karena untuk melawan Barat harus meniru peradaban Barat. Maka yang ditonjolkan adalah bagaimana bangsa Timur berjuang untuk membebaskan diri (Akbar, 2017) dari pengaruh perkembangan buruk yang terjadi.

Nasionalisme memainkan peran vital dalam langkah pertama untuk membangun bangsa. Bangsa menurut Anderson (2008) adalah sesuatu yang terbayang karena para anggota bangsa terkecil sekali-pun tidak tahu dan takkan kenal sebagian besar anggota lain, tidak bertatap muka dengan mereka, bahkan mungkin tidak pula pernah mendegar tentang mereka. Namun dibenak setiap orang yang menjadi anggota bangsa itu hidup sebuah bayangan tentang kebersamaan mereka. Keberagaman serta perbedaan corak dan karakteristik daerah tidak harus menghilangkan semangat jiwa dan persatuan, dimana hanya akan secara bersama membela dan menjunjung tinggi peradaban bangsa. Menurut Ismawati (2018) nationalism is a group of individuals who want to unite with other individuals with impulse of the will and the psychical need. It is the highest allegiance that individuals give to nation and state.

Aktivitas pengaplikasian nilai nasionalisme bukan dari suatu hal yang sudah ada dan menjadi suatu yang harus diikuti berdasarkan jejak sejarahnya, namun nasionalisme yang sudah ada dijadikan bahan pelajaran dan cerminan bagi generasi selanjutnya ketika dihadapkan dengan persoalan demikian. Nasionalisme yang akan dihadapi adalah yang berkembang saat dimana generasi dipengaruhi oleh adanya krisis serta pergolakan yang mengguncang aspek 
kehidupannya. Seperti penelitian menarik yang datang dari Juergensmeyer (2016), bahwa kebangkitan nasionalisme agama diseluruh dunia, akibat adanya tanggapan terhadap krisis sosial dan politik. Krisis geopolitik umum yang dialami seluruh dunia tidak dapat dipungkiri lagi akan muncul panasea baru atau obat yang ampuh dengan melibatkan agama, karena dianggap sebagai satu-satunya kemudian yang stabil baik dalam ranah ekonomi dan politik. Tatanan agama dari moral akan terus muncul sebagai solusi yang menarik, namun dari peneliti ini muncul pertanyaan dapatkah para nasionalis religius ini berhasil? Serta apakah bangsa-bangsa dapat bertahan lama hanya dengan memanfaatkan solusi-solusi religious?. Pertanyaan ini akan terus muncul seiring dengan perkembangan dunia saat ini yang menuntut adanya suatu kestabilan. Bagian ini memberikan penekanan terhadap bagimana identitas bangsa dengan nilai luhurnya dalam menghadapi dinamika krisis yang membuming di kalangan masyarakat luas.

Nasonalisme sensitif terhadap perkembangannya. Karena Nasionalisme adalah wacana yang sangat fleksibel dan dapat beradaptasi. Salah satu definisi konten yang mengarah pada pendapatnya Brubaker (2017) menyatakan "Content of national culture or national identity is specified in civilizational language, civilizationism can be understood as a form of nationalism, a way of talking about "the nation". Uraian diatas mengatakan bahwa muatan nasionalisme menjadi bagian yang tidak terpisahkan dari peradaban, dan peradaban itu juga dipahami sebagai bentuk nasionalisme.

Bertolak dari hal tersebut, ada kekhawatiran akan nilai baik yang tersimpan dalam diri anak bangsa. Berbagai persoalan muncul dari sumber tindakan yang beragam, menjadi tantangan bagi anak bangsa dalam menghindari perilaku tidak baik dan menjawab tantangan yang bergejolak. Karena jika tidak, generasi akan mudah tergerus dengan hal yang dia hadapi. Persoalan ini sudah bergeser ke gagasan ancaman. Ancaman ini akan terus ada selama semua masyarakat bangsa tidak saling bersatu padu dalam memecahkan masalah, sentimen antara kelompok tetap terus terjadi, sehingga kehancuran terus merajalela di dunia terutama di bangsa Indonesia tercinta. Apalagi dengan islam yang saat ini menjadi musuh bersama dari setiap negara sekuler.

Ada yang menarik dari penelitian Barr \& Govindasamy (2010) agama, etnis, dan identitas nasional telah lama penuh dengan ketegangan yang tidak menyenangkan. Penelitian ini mengambarkan adanya peran nasionalisme religius yang kurang memberikan peluang bagi kaum minoritas. Sehingga kaum minoritas semakin dikucilkan dan tertindas. Padahal kaum minoritas sudah seharusnya untuk dihargai. Bahkan penelitian Antal (2008) tentang hubungan antara 
Faidin, Agus Mulyana, Helius Sjamsuddin

Muatan Lokal Nahdlatul Wathan untuk Menggali Nilai-Nilai Nasionalisme

di Madrasah Aliyah Kota Mataram

penyebaran wacana kewarganegaraan nasionalis religius di ruang kelas dan konflik antar agama dalam konteks dua demokrasi yang sedang berkembang. Memberikan gambaran bahwa penerimaan ideologi-ideologi ini tampaknya berkorelasi dengan peningkatan konflik antar agama, tidak stabilnya lingkungan sosial, dan terjadi intervensi dalam konteks demokrasi.

Bagi negara Indonesia, krisis multidimensi terhadap rasa kebangsaan atau nasionalisme di tengah derasnya gejala degradasi dan dekadensi nasionalisme ialah berkembangnya gerakan transnasional yang membawa dogma-dogma agama, yang dihubungkan dengan organisasi Islam seperti Nahdlatul Ulama, Muhammadiyah, Persis, dan Nahdlatul Wathan. Krisis ini menjadi tantangan tersendiri bagi organisasi khususnya Nahdlatul Wathan. Hardian (2016) munculnya berbagai gerakan trans-nasionalisme dalam segi-segi tertentu mencerminkan masih adanya ruang yang belum berhasil diisi oleh Nahdlatul Wathan, dan ormas Islam di Indonesia, sehingga muncul pandangan masyarakat yang seolah-olah berfikir bahwa Sekolah Nahdlatul Wathan melekat dengan anti nasionalisme, sehingga harus dihilangkan.

Untuk menutupi gap yang terjadi, maka peran lembaga pendidikan begitu penting, khususnya pada sekolah Nahdlatul Wathan, karena lembaga pendidikan merupakan sarana untuk membentuk karakter generasi bangsa, yang dapat mentransfer nilai nasionalisme. Melihat hasil Survei Lembaga Kajian Islam dan Perdamaian (LaKIP) pada 1.600-an peserta didik dan guru di SMP dan MA Islam, yang dilakukan pada Oktober 2010 hingga Januari 2011, hasilnya menunjukan bahwa terdapat 41,8 hingga 63,8 persen responden yang mendukung intoleransi dan kekerasan (Fauzi, I, 2011). Sangat disayangkan apabila pendidikan tidak mampu menopang berbagai gejala demikian. Sehingga generasi harus merasakan siraman ketidakbaikan secara berkesinambungan dalam aspek kehidupannya.

Pendidikan berakar dari nilai. Nilai akan mampu mengaktifkan intelektual anak secara lebih. Nilai akan memberikan pengaruh besar terhadap peningkatan kemampuan serta kecerdasan masyarakat. Ada beberapa nilai ajaran nasionalisme yang bisa di ajarkan dalam pendidikan Nahdlatul Wathan (Nahdi, 2017) sebagai berikut:

"Wujud nasionalisme religius Nahdlatul Wathan ialah nasionalisme yang tidak anti bekerjasama dengan pihak luar yang berbeda mazhab dan keyakinan, bahkan sejumlah pendidik beragama Hindu mengajar di lembaga pendidikan Nahdlatul Wathan. Termasuk memberikan kesempatan pendidikan kepada kaum perempuan, dengan mendirikan Madrasah Nahdlatul Banat 
Diniyah Islamiyah (NBDI) di saat pendidikan bagi perempuan masih dianggap tabu. Pemikiran dan pandangan yang memisahkan agama dan negara, sebab agama dan negara dipandang sebagai "dualitas yang saling berelasi, bermediasi, dan melengkapi”. Mencerminkan sikap rekonsiliasi antara dimensi negara dan agama. Sikap ini sangat relevan untuk bangsa Indonesia yang multikultur. Secara filosofis, antara agama dan negara diposisikan sama dalam suatu tarikan nafas, yakni membangun agama berarti juga membangun Negara. Sebagai bagian dari upaya untuk mencerdaskan bangsa dan pemerataan pembangunan di Indonesia. Semangat nasionalisme dan patriotisme tercermin dalam karya TCKH Muhammad Zainuddin Abdul Madjid seperti Lagu perjuangan ya fata sasak, syair Wasiat renungan masa, dan karya tulis sebagai upaya memperkenalkan bahasa Indonesia sebagai bahasa persatuan bangsa Indonesia..."

Internalisasi dan kristalisasi nilai-nilai nasionalisme dalam ajaran Nahdlatul Wathan dapat memperkuat bangsa dalam menjawab tantangan yang sulit diduga, serta menjadikan nilai nasionalisme sebagai wujud identitas bangsa yang tak terpisahkan dalam kehidupan, hal ini akan mempermudah dan mengembangkan aktivitas secara bertahap dan berkelanjutan.

\section{Hasil dan Pembahasan}

Pelaksanaan pembelajaran muatan lokal ke Nahdlatul Wathan-an dalam menggali nilai-nilai nasionalisme dilakukan dalam setiap materi pokok bahasan satu kali pertemuan dalam seminggu dengan alokasi waktu 2×45 menit. Pertemuan pertama membahas peran Nahdlatul Wathan dalam pembangunan bangsa. Pertemuan kedua, dipergunakan oleh guru untuk membahas peran pendiri Nahdlatul Wathan dalam pembangunan bangsa.

Dalam materi ini, guru menyampaikan, dan Peserta didik menerima serta menyerap pembelajaran nahdlatul wathan untuk perannya dalam bidang pendidikan, sosial, dan dakwah islamiyah. Di bidang pendidikan materinya ialah membentuk generasi yang beriman dan bertakwa, karena slogan Nahdlatul Wathan ialah pokoknya-pokoknya iman dan taqwa. Organisasi Nahdlatul Wathan mengajak kepada generasi muda untuk mengembangkan semangat keimanan dan ketaqwaan sebagai dasar dalam membentuk semangat keagamaan dan semangat kebangsaan dalam mencerdaskan umat agar sejajar dengan bangsa-bangsa yang lain yang lebih maju. Guru menganggap bahwa seorang yang beriman dan bertaqwa secara benar dan konsisten maka akan berdampak 
Faidin, Agus Mulyana, Helius Sjamsuddin

Muatan Lokal Nahdlatul Wathan untuk Menggali Nilai-Nilai Nasionalisme

di Madrasah Aliyah Kota Mataram

positif bagi orang tersebut, baik dalam ranah keagamaan maupun kebangsaan. Materi yang disajikan guru adalah tentang tokoh pendiri Nahdlatul Wathan TCKH M. Zainuddin Abdul Madjid yang mempelopori pendidikan sekaligus yang mendirikan dua Madrasah yaitu Madrasah NWDI dan Madrasah NBDI yang sampai sekarang berkembang dan berkonstribusi untuk pembangunan pendidikan-pendidikan terhadap perkembangan Islam di Pulau Lombok.

Peran Nahdlatul Wathan dalam bidang sosial. Guru menyampaikan materi tentang banyaknya sejarah yang ditorehkan oleh Nahdlatul Wathan, dimana ia berada sebagai organisasi sosial kemasyarakatan, kemudian menjadi salah satu komponen pembangunan untuk peningkatan kesejateraan masyarakat. Dilanjutkan dengan penjelasan Nahdlatul Wathan yang merupakan komunitas dalam mengembangkan nilai-nilai Islam dalam kehidupan yaitu amal jariyah, gotong royong, keikhlasan berjuang, pemberian santunan kepada: fakir miskin, yatim piatu, anak-anak terlantar, para lansia, dan penderita cacat, kemudian melaksanakan pembangunan dan pemeliharaan rumah-rumah ibadah, menghidupkan dan menyuburkan jama'ah syafa'ah dan lain sebagainya. Terakhir peran Nahdlatul Wathan dalam Bidang dakwah Islamiyah. Guru menjelaskan berdasarkan Anggaran Dasar "Nahdlatul Wathan. Dalam hal ini, dilakukan dengan memberikan materi terkait perjalanan Maulana Syeikh saat kembali dari Makkah dengan memberikan contoh prestasi proses dakwah yang dilakukan beliau.

Aktivitas pembelajaran sejarah Nahdlatul Wathan tidak terlepas dari ketiga ranah gerakannya. Karena misi gerakan adalah pada bidang pendidikan, sosial, dan dakwah. Sehingga bagaimana ketiga aspek demikian dapat ditanamkan serta diserap oleh peserta didik sebagai identitas dirinya dalam organisasi NW. Berjalannya tiga bidang yang teraktualisasi dalam berbagai program dan kelembagaan, telah membangun masyarakat yang bergabung secara total kepada Nahdlatul Wathan (Parhanudin, 2012). Dengan muatan-muatan nilai yang positif bagi kebertahanan generasi bangsa.

Pelaksanaan proses pembelajaran Nahdlatul Wathan berlangsung secara aktif dan menyenangkan dengan lebih memunculkan aktivitas diskusi dan tanya jawab. Guru berusaha menyelipkan pendekatan saintifik $5 \mathrm{M}$ (Mengamati, Menanya, Mencoba, Menalar, dan Menyaji), sewalaupun belum sampai pada tahap mencipta, namun hal ini dapat membantu proses pemerolehan pembelajaran bagi peserta didik.

Proses diskusi dilakukan dengan posisi duduk melingkar saling berhadapan, yang dibagi menjadi tiga kelompok. Diskusi berlangsung sangat menarik, karena 
peserta didik sangat kompak dalam mengungkapkan serta menanggapi apa yang disampaikan oleh peserta didik yang lain. Dan setiap kelompok membicarakan pokok bahasan yang berbeda-beda, ada yang membahas tentang peran Nahdlatul Wathan dalam bidang pendidikan, kemudian ada yang membahas peran Nahdlatul Wathan dalam bidang sosial, dan peran Nahdlatul Wathan dalam bidang dakwah islamiyah.

Berikutnya peserta didik diminta untuk merespon peran Nahdlatul Wathan berdasarkan apa yang telah didiskusikan. Dengan satu per satu, peserta didik melaluinya dengan baik, mereka mengungkapkan pendapat dari hasil pengamatannya terhadap buku serta berdasarkan isi hasil diskusi sebelumnya. Berikut alur kegiatan pembelajaran saat dimana aktifnya peserta didik dalam mengungkapkan hasil pengamatan dan analisisnya.

Saat pengamatan, diidentifikasi beberapa hasil ungkapan peserta didik terhadap hasil kerja pengamatan pembelajarannya. Uraiannya dapat dilihat sebagai berikit.

1. Peserta didik (Vera): Peserta didik mengungkapkan bahwa ditengahtengah kebodohan masyarakat, Maulana Syeikh membangun lembaga pendidikan Madrasah Nahdlatul Wathan dengan tujuan mencerdaskan masyarakat. Karena pada saat itu masyarakat kebanyakan berada dalam kebodohan, hanya satu yang berpendidikan dari sekian banyak warga Lombok.

2. Peserta didik (Alamin), Peserta didik mengungkapkan bahwa pada materi bidang sosial, peran Nahdlatul Wathan tidak harus mengejutkan, karena dalam Nahdlatul Wathan sudah banyak berperan dalam mengajarkan bagaimana hidup dengan menghargai perbedaan, dengan pembuktian Peserta didik sendiri terhadap posisinya sebagai orang luar yang tidak tahu Nahdlatul Wathan sebelumnya, namun bisa diterima, dalam hal ini pula mereka diajarkan untuk saling menggunakan bahasa Indonesia dengan keberagaman latar belakangnya, serta situasi kondisi hidup di lingkungan Lombok terlihat rukun dalam membantu antar berbeda keyakinan.

Nasionalisme memang menjadi salah satu bingkai perbedaan, karena nasionalisme lebih dekat pada munculnya kekacauan atas ketidaksamaan antar agama, ras, adat istiadat, serta gaya hidup dalam masyarakat. Nationalism is a complex concept that involves many different aspects of individual citizens' thoughts and beliefs regarding their country, state and people (Woods, J. S. \& 
Faidin, Agus Mulyana, Helius Sjamsuddin

Muatan Lokal Nahdlatul Wathan untuk Menggali Nilai-Nilai Nasionalisme

di Madrasah Aliyah Kota Mataram

Dickson, 2016). Maka masyarakat dalam lingkungan yang sama, secara bersamaan berkumpul dengan latar belakang berbeda harus berdiri secara bersama maju dan mengembangkan bangsa secara utuh.

Setelah proses menanggapi berjalan, maka masuklah proses mengomunikasikan. Peserta didik mempresentasikan hasil catatan terkait peran Nahdlatul Wathan dalam pembangunan bangsa. Presentasi dilakukan tidak secara berkelompok, tetapi diwakili oleh satu orang pada masing-masing kelompok, dan yang berkesempatan untuk menyampaikan sebagai berikut:

1. Peserta didik (M Fahroji), menjelaskan bahwa materi tentang peran Nahdlatul Wathan dalam bidang sosial sangat banyak disampaikan oleh guru melalui motivasi, dan didukung dengan hasil diskusinya tentang peran Nahdlatul Wathan dalam ranah sosial. Banyak nilai yang diidentifikasi, diantaranya; membantu masyarakat, dan mengajari masyarakat.

2. Peserta didik (Hariayadi), mewakili kajian bidang keagamaan, Peserta didik memulainya dengan salam, dan dijawab oleh teman-temannya secara serentak. Dia menyampaikan bahwa Nahdlatul Wathan adalah organisasi keagamaan yang cinta damai, dan cinta akan rasa satu berbangsa. Peserta didik menekankan bahwa dalam nilai ajarannya banyak diterapkan di Hizib, pengintegrasian nilai ajaran NW terangkum dalam sebuah buku kumpulan tulisan Pendiri Nahdlatul Wathan (Hizib) yang memuat doa-doa. Ungkapannya Hizib dapat mempermudah masyarakat dalam segala urusan dengan syarat harus meyakini. Disisi lain, membuat hati menjadi tenang.

3. Peserta didik (Vera), Peserta didik berkesempatan mewakili kelompok untuk menyampaiakan peran Nahdlatul Wathan dalam bidang pendidikan, Hasil diskusinya bahwa peran Nahdlatul Wathan dalam lingkup pendidikan secara nyata dapat dilihat dari banyaknya gedung pendidikan yang didirikan, salah satunya lembaga pendidikan Nahdlatul Wathan. Yang berdampak pada banyaknya masayarakat yang berpendidikan, dan menjadi guru, dosen, bahkan pengusaha, serta bupati/ gubernur, yang kesemuanya adalah hasil dari peran Nahdlatul Wathan dalam mencerdaskan kehidupan berbangsa dan bernegara.

Penyampaian peserta didik memberikan suatu jalan yang sangat baik, karena pelaksanaan pembelajaran muatan lokal ke Nahdlatul Wathan-an sudah dapat dipahami dan dirasa oleh peserta didik secara maksimal. Dengan 
kenyataan bahwa peran pendiri Nahdlatul Wathan begitu menggugah semangat mereka untuk mengaktualisasikannya dalam kehidupan sekarang dan kedepan. Baik dalam segi pendidikan Islam dengan gelaran pengajian-pengajian di langgarlanggar dan masjid-masjid (Madjid, 2017) dan sekolah umum, memberikan kursus-kursus keterampilan dalam bidang pertanian, menjahit, perkoperasian, perbengkelan, dan sebagainya. Dengan tujuan agar santri memiliki keterampilan khusus dalam bidang tertentu (Madjid, 2017). Syi'ar sosial dan dakwah islamiyah. Terakhir, Guru masuk dengan mengungkapkan suatu kesimpulan dari apa yang sudah didiskusikan dan dipelajari oleh peserta didik.

Data hasil penelitian menunjukan bahwa proses pembelajaran muatan lokal ke Nahdlatul Wathan-an dalam menggali nilai-nilai nasionalisme dilaksanakan dengan menggunakan metode ceramah, diskusi, dan tanya jawab, serta masih dengan pendekatan saintifik, namun secara nyata dalam pelaksanaannya tidak secara penuh diintegrasikan.

Fase awal, guru menjelaskan secara rinci peran pendiri Nahdlatul Wathan dalam pembangunan bangsa terutama dalam ranah perjuangan, sebagai salah satunya "Syaikh Zainuddin". Liku-likunya dalam menghadapi tantangan dan hambatan dalam memerdekakan kehidupan masyarakat dari keterbelakangan, sehingga dengan hasil perjuangannya sebagai tokoh pendidikan dan ulama, serta mujahid agama, nusa, dan bangsa menjadikannya memiliki status sebagai pahlawan. Pahlawan dalam pendidikan, sosial, dan dakwah islamiyah.

Guru menambah wawasan Peserta didik dengan menyampaikan alur pergerakan tokoh Zainul Madjid “ sebagai perintis kemerdekaan di NTB dengan gerakan "Al Mujahidin" yang bergabung dengan gerakan-gerakan rakyat pembela kemerdekaan. Yang menjadikan Madrasah Nahdlatul Wathan Diniyah islamiah (NWDI) dan Madrasah Nahdlatul Banat Diniyah Islamiyah (NBDI), sebagai pusat pergerakan kemerdekaan.

Terlepas dari itu, Motivasi selalu disentilkan oleh guru sebagai penguat kepekaan peserta didik akan perjuangan pendiri NW. Guru berkata "pendiri Nahdlatul Wathan adalah seorang Inovator, dimana beliau adalah seorang yang pintar, juga rajin sehingga bisa di contohi, salah satunya ialah ketekunannya dengan tiada waktu tanpa belajar. Begitulah falsafah beliau waktu itu, juga pada saat melawan penjajah, Maulana Syaikh lah yang merancang strategi perjuangan dikarenakan ilmunya".

Fase selanjutnya, saat dimana peserta didik diberikan kesempatan untuk berdiskusi dan tanya jawab kembali. Antara guru dan peserta didik, serta antara 
Faidin, Agus Mulyana, Helius Sjamsuddin

Muatan Lokal Nahdlatul Wathan untuk Menggali Nilai-Nilai Nasionalisme

di Madrasah Aliyah Kota Mataram

peserta didik dengan peserta didik lainnya. Tanya jawab demikian terlihat pada dialog berikut ini.

1. Peserta didik (Julfan): Peserta didik memulai pertanyaan dengan mengucap salam terlebih dahulu, dan dijawab oleh peserta didik lainnya secara serentak. Julfan bertanya, "seperti apakah kepemimpinan Maulana Syeikh dalam mendirikan Nahdlatul Wathan?".

Guru : Guru menjawab, "Maulana Syeikh dikenal sebagai ulama besar di Indonesia karena ilmu yang dimiliki beliau luas dan mendalam. Demikian pula karisma beliau sebagai sosok figur ulama demikian besar. Beliau adalah tokoh panutan yang sangat berpengaruh karena kearifan dan kebijaksanaannya. Pola kepemimpinan yang Maula Syeikh contohkan ialah kharisma yang melekat padanya dalam memperoleh dukungan masyarakat. Bahkan Maulana Syeikh saat dengan peserta didiknya nya tidak pernah mempersulit semua peserta didik yang hendak bertemu. Sikap low profile tersebut membuat Maulana Syeikh selalu dekat dengan semua peserta didik, tanpa mengurangi kewibawaan dan kharismanya. Keluhan dan kesulitan peserta didik selalu diperhatikan, didengar, dan dicarikan solusinya. Serta sering kali beliau memberikan apresiasinya terhadap para peserta didik yang menunjukkan perkembangan positif dalam perjuangan Nahdlatul Wathan, baik melalui sikap, maupun ucapan beliau". Akbari, Sari, Siwi, \& Rahayu (2018), "value can be interpreted as inherent characters or qualities of an object. It means that figure's character, thinking, and action can be obtained to do well for others". Nilai/Sikap yang baik adalah hal yang terlihat nyata dan alami dari dalam diri seseorang yang berjasa dan berharga, seseorang tersebut sebagai figur bagi peningkatan kualitas kehidupan masyarakat.

Pendidikan bukan hanya sebatas mengajar dikelas, pendidikan sangat membuka ruang, dimanapun dan kapanpun manusia berada. Yang diharapkan tokoh pendiri Nahdlatul Wathan agar bagaimana anak bisa belajar bermakna berdasarkan fungsinya dan misi gerakan Nahdlatul Wathan pun tercapai. Makna pendidikan dapat dipahami sebagai "proses memanusiakan atau membimbing" sebagaimana dikemukakan di atas, maka fungsi pendidikan menjadi penting artinya bagi masyarakat, dalam hal ini peserta didik. Fungsi utama pendidikan menurut Nahdlatul Wathan adalah pertama, mentransfer dan menanamkan nilai-nilai, baik nilai-nilai llahiyah maupun nilainilai 
insaniyah (transfer of values) dalam rangka memelihara keutuhan individu sekaligus keutuhan dan kesatuan masyarakat sebagai prasyarat bagi kelangsungan hidup (survive) masyarakat dan peradaban. Kedua, mentransfer pengetahuan (transfer of knowledge) sesuai dengan peranan yang diharapkan (Usman, 2010).

2. Peserta didik (Nera): "Apakah yang memotivasi Maulana Syeikh melakukan perjuangan membela masyarakat di Lombok ini?"

Guru : Guru mengapresiasi terlebih dahulu apa yang ditanyakan oleh peserta didik. Kemudian menjawabnya bahwa "Maulana Syeikh memiliki motivasi tinggi untuk menjaga harkat dan martabat bangsa terutama masyarakat di Pulau Lombok, karena menurut Maulana Syeikh para Kolonial merupakan penjajah yang tanpa rasa terimakasih, banyak cara perlawanan yang dilakukan maulana Syeikh ialah dengan membodohi pemerintah kolonial ketika pendidikan yang ia dirikan ingin dibubarkan. Maulana Syeikh menyatakan bahwa pendidikan yang ia dirikan adalah pendidikan yang mengajarkan kebaikan karena menggunakan bahasa Arab, dengan demikian katanya sekolah Nahdlatul Wathan tidak melawan namun haya sebatas mengajarkan agama. dengan perkataan itu pemerintah kolonial menerima sekolah tersebut. Padahal disekolah ini ditanamkan misi perjuangan. Zuhdi, 2014 (dalam Kulap, Warto, \& Joebagio 2017) mengatakan bahwa "history will be able to establish nationalism and define the identity of people". Penjelasan guru mempertegas bagaimana identitas seorang pendiri NW dalam mempertahankan bangsanya.

3. Peserta didik (Alamin) : peserta didik bertanya, "apakah benar Nahdlatul Wathan adalah organisasi yang membela masyarakat lemah?".

Guru: ya...(kata guru!), memang Nahdlatul Wathan adalah organisasi pembela karena tidak hanya dalam masa penjajahan namun sampai saat sekarang pun organisasi Nahdlatul Wathan dapat meringankan kehidupan masyarakat dengan disediakan sekolah gratis, hidup gratis, dan makan gratis. Artinya Nahdlatul Wathan sangat berperan dalam mensejahterakan kehidupan masyarakat.

Berdasarkan hasil diskusi dan tanya jawab diatas, kemudian peserta didik oleh gurunya diberikan kesempatan untuk menyimpulkan sendiri hasil dari proses tanya jawab tersebut. Dapat dikatakan bahwa proses yang dilaksanakan ini sangat menarik dan komunikatif karena 
Faidin, Agus Mulyana, Helius Sjamsuddin

Muatan Lokal Nahdlatul Wathan untuk Menggali Nilai-Nilai Nasionalisme

di Madrasah Aliyah Kota Mataram

antara peserta didik dan guru saling melengkapi dan memberikan suatu arah pembelajaran yang bernilai positif.

Berkenaan dengan pengintegrasian pembelajaran muatan lokal ke Nahdlatul Wathan-an dalam peningkatan nilai-nilai nasionalisme dapat terlihat dalam aktifitas pembiasaan yang dilakukan oleh lembaga Nahdlatul Wathan sendiri. Terlepas dari dalam mata pelajaran wajib dan pilihan sebagai muatan lokal sejarah, nilai nasionalisme-pun diajarkannya diluar kelas, seperti membaca Hizib, Upacara, pengajian, kegiatan ekstra kurikuler, dan kegiatan Hultah NWDI (Nahdaltul Wathan Diniyah Islamiyah).

Aktivitas demikian sebagai bentuk sikap meneladani dan bentuk nyata penghargaannya terhadap para pahlawan. Dalam kehidupan sehari-hari, dapat melatih diri supaya memiliki sifat-sifat kepahlawanan dan semangat cinta bangsa dengan mulai menghargai para pahlawan bangsa untuk mengingat jasa-jasa mereka. Selain itu, mencontoh beberapa sikap pahlawan dengan mengimplementasikannya dalam hal menghargai kepala sekolah, guru, dan teman, dan bersedia meminta dan memaafkan (Aman, 2011). Dilanjutkan dengan pendapat (Wiriaatmadja, 2002) nilai nasionalisme yang perlu ditanamkan pada peserta didik ialah menghargai orang lain (terutama para pahlawan).

Bentuk menghargai ini sangat penting, sebagaimana yang dicontohkan oleh tokoh Nahdlatul Wathan, dalam bukunya Nu'man, sebagai berikut:

Maulana Syeikh sebagai tokoh pendiri Nahdlatul Wathan telah mencontohkan perilaku yang demikian sebagai bukti ketika beliau mengungkapkan rasa hormatnya kepada gurunya bahkan bukti dari penghormatanya, Maulana Syeikh mendirikan pondok pesantren hasabiyah Nahdlatul Wathan di Jenggik Lombok Timur, Madrasah untuk Gurunya yang bernama Maulanasy Syeikh Hasan Muhammad Al Masysyath. Penghargaan untuk gurunya Maulanasy Syeikh Sayyid Muhammad Amin Al Kutbi ditunjukan dalam bentuk pondok pesantren Aminiyah Nahdlatul Wathan di Bonjeruk Lombok Tengah.

Bahkan dengan peserta didiknya saja Maulana Syeikh selalu mendengarkan apa yang menjadi keluhan mereka dan kemudian dicarikan solusi atau jalan penyelesaian dengan penuh kearifan dan kebijaksanaan, serta tidak pernah merugikan pihak yang lain (Nu'man, 1988). Interaksi yang dibangun oleh Maulana Syeikh memiliki makna atau simbolsimbol yang terdapat dilingkungan pendidikan. Dengan 
demikian, makna dan kebenaran sangat menyeluruh, keduanya memiliki keterkaitan dan bersifat integral yang tidak dapat dipisahkan. Seorang guru sejarah memiliki peran penting dalam proses pembelajaran sejarah, untuk itu dibutuhkan kesadaran yang tinggi dalam menginterpretasi makna yang ada dalam peristiwa-peristiwa sejarah secara objektif (Setiawati, 2011).

Nilai menghargai sangat tidak memandang tingkatan serta tahta seseorang, selagi itu bernilai postif bagi diri dan orang lain. Oleh sebab itu, cerminan perilaku pendiri Nahdlatul Wathan mengingatkan dan menunjukan bahwa peserta didik juga harus dapat menghargai jasa pahlawan walau mereka sendiri belum pernah melihatnya. Sikap ini tentu harus dimiliki oleh peserta didik dalam rangka membangkitkan semangat belajar untuk lebih arif dalam berinteraksi dan menghargai orang lain terutama guru dan temannya sendiri.

\section{Simpulan}

Pelaksanaan muatan lokal Nahdlatul Wathan menjadi bagian yang tak terpisahkan dari konten nilai-nilai nasionalisme. Nilai-nilai nasionalisme yang terdapat di dalamnya antara lain: menghargai pahlawan, dan mempertahankan identitas ketimuran. Keduanya bisa membangun perubahan perilaku peserta didik secara perlahan ke arah yang lebih baik. Karena nilai-nilai tersebut sudah melekat pada diri Peserta didik yang telah belajar melalui kegiatan di kelas dan di luar kelas, di luar kelas yakni membaca Hizib, upacara, milad NWDI, dan mengedepankan salam pada setiap orang yang lebih dewasa. Sementara nilai nasionalisme Nahdlatul Wathan juga secara khusus diintegrasikan ke dalam mata pelajaran yang ada, atau menjadi sebuah mata pelajaran berdiri sendiri dalam pelaksanaanya. Namun secara pasti, hal ini dilakukan dengan meliputi kegiatan awal, kegiatan inti dan kegiatan penutup. 
Faidin, Agus Mulyana, Helius Sjamsuddin

Muatan Lokal Nahdlatul Wathan untuk Menggali Nilai-Nilai Nasionalisme

di Madrasah Aliyah Kota Mataram

\section{Daftar Rujukan}

Agustyaningrum, H., Herman, H., Waluyo, J., \& Sumarwati, S. (2018). Nationalism Values of Characters in Nh. Dini's Novels. International Journal of Multicultural and Multireligious Understanding, 5(6), 93-100.

Akbar, N. (2017). Ketika Nasionalisme dan Kosmopolitanisme Mampu Berdampingan: Refleksi Kritis Gagasan Kosmopolitanisme dari Bawah ala Al Afghani. Prosiding Internasional Konferens. Yogyakarta: SDU Pres.

Akbari, S., Sari, N. K., Siwi, D. A., \& Rahayu, M. H. S. (2018). Design of Teaching and Learning Materials based on the Values of Local Heroic Struggle in Sukoharjo. International Journal of Multicultural and Multireligious Understanding, 5(6), 28-33.

Altikulaç, A., \& Sabanci, O. (2017). Nationalism Perceptions of Pre-Service Social Studies Teachers in Turkey. Journal of Education and Practice, 8(8), 237256.

Aman. (2011). Model Evaluasi Pembelajaran Sejarah. Yogyakarta: Ombak.

Anderson, B. (2008). Imagined Communities (Komunitas- komunitas Terbayang). Yogyakarta: Kerjasama Institusi dan Pustaka Pelajar.

Antal, C. (2008). Reflections on religious nationalism, conflict and schooling in developing democracies: India and Israel in comparative perspective. Compare, 38(1), 87-102.

Barr, M. D., \& Govindasamy, A. R. (2010). The Islamisation of Malaysia: Religious nationalism in the service of ethnonationalism. Australian Journal of International Affairs, 64(3), 293-311.

Brubaker, R. (2017). Between nationalism and civilizationism: the European populist moment in comparative perspective. Ethnic and Racial Studies, 40(8), 1191-1226.

Fauzi, I, A. (2011, March). Radikal Dulu, Teroris Kemudian. Koran Tempo (Online). p. A.10.

Hardian, Y. (2016). Pembelajaran Sejarah Gerakan Nasional Kemuhammadiyahan Untuk Menggali Nilai-Nilai Nasionalisme Peserta Didik. Universitas Pendidikan Indonesia, Jakarta.

Ismawati, E. (2018). Nationalism in Indonesian Literature as Active Learning Material. International Journal of Active Learning, 3(1), 33-38.

Juergensmeyer, M. (2016). The worldwide rise of religious nationalism. Journal of International Affairs, 50(1), 1-20.

Kulap, M., Warto, M., \& Joebagio, H. (2017). Nationalism of Nani Wartabone: Nation Character Building Foundation of Indonesia. International Journal of Multicultural and Multireligious Understanding, 4(3), 12-21.

Madjid, M. Z. A. (2017). Naskah Akademik Pengusulan Gelar Pahlawan Nasional 
Tuan Guru Kyai Haji Muhammad Zainuddin Abdul Madjid: Biografi TCKH Muhammad Zainuddin Abdul Madjid sebagai Pahlawan Nas. Bogor.

Nahdi, K. (2017). TGH M Zainuddin Abdul Madjid dan Gerakan Kebangsaan. Bogor.

Nu'man, D. (1988). Nahdlatul Wathan Organisasi Pendidikan, Sosial dan Dakwah Islamiyah. Lombok Timur: Pengurus Daerah Nahdlatu Wathan.

Nusarastriya, Y. H. (2018). Sejarah Nasionalisme Dunia dan Indonesia. Retrieved October 29, 2018, from Google File pdf website: http://docplayer.info/68183789-Sejarah-nasionalisme-dunia-dan-indonesiaoleh-dr-drs-yosaphat-haris-nusarastriya-m-si-abstract.html

Opafola, S. . (2016). Implications of ethnic nationalism: The Niger delta region of Nigeria as a case study. International Journal of Peace and Development. Studies, Vol.7(7).

Parhanudin, M. A. (2012). Nahdlatul Wathan dan Masyarakat Sipil (Studi Gerakan Sosial atas Manifestasi Civil Society Pada Masyarakat Lombok). Jurnal Agama Dan Hak Azazi Manusia, 2(1).

Setiawati, D. (2011). Interaksi Simbolik dalam Kajian Sejarah. Jurnal Agastya, 1.

Usman. (2010). Pemikiran Pendidikan Nahdlatul Wathan di Lombok. Jurnal Penelitian Keislaman, 6,(2), 445-466.

Wiriaatmadja, R. (2002). Pendidikan Sejarah Indonesia, Perspektif Lokal, Nasional dan Global. Bandung: Historia Utama Press.

Woods, J. S. \& Dickson, B. J. (2016). Victims and Patriots: Disaggregating Nationalism in Urban China. Journal of Contemporary China.

Yuniyati, W.A., S, Agung. L, and W. (2018). Boedi Oetomo: the Multi Ethnic and Pioneering Organization to the Spirit of Nationalism. International Journal of Multicultural and Multireligious Understanding, 5(3). 